\title{
STUDI PENGARUH VARIASI TIPE PENGAKU DIAGONAL PADA STRUKTUR BANGUNAN BAJA BERTINGKAT TERHADAP PERPINDAHAN LATERAL
}

\author{
Clement Kristianto Halim ${ }^{1}$, Leonardus Setia Budi Wibowo², \\ Muhammad Shofwan Donny Cahyono ${ }^{3}$, Norman Ray ${ }^{4}$ \\ ${ }^{1}$ Clement Kristianto Halim, Universitas Widya Kartika, clementkrish98@ gmail.com \\ ${ }^{2}$ Leonardus Setia Budi Wibowo, Unversitas Widya Kartika, leonarduswibowo@widyakartika.ac.id \\ ${ }^{3}$ Muhammad Shofwan Donny Cahyono, Universitas Widya Kartika, shofwandonny@widyakartika.ac.id \\ ${ }^{4}$ Norman Ray, Universitas Widya Kartika
}

\begin{abstract}
ABSTRAK
Pada studi ini dilakukan analisis terhadap kinerja struktur bangunan baja bertingkat ( 5 dan 15 lantai) dengan 3 variasi tipe pengaku diagonal (Inverted V, Single Diagonal dan X-Bracing) dan gedung terbuka. Analisis dilakukang dengan bantuan software SAP 2000 v14. Hasil dari analisis ini akan dibandingkan dari 4 tipe gedung dan 2 jenis ketinggian. Melalui studi analisis ini dilakukan perbandingan perpindahan dan simpangan masing-masing gedung. Gedung dengan tambahan pengaku diagonal memiliki nilai perpindahan yang lebih kecil dibanding struktur gedung terbuka. Gedung dengan tipe pengaku diagonal XBracing mampu mereduksi perpindahan paling besar dengan presentase 30,78\% untuk gedung 5 lantai dan 18,84\% untuk gedung 15 lantai. Taraf kinerja struktur bangunan 5 lantai termasuk dalam Immediate Occupancy untuk semua variasi pengaku diagonal. Hal ini menunjukkan bahwa penggunaan tipe pengaku diagonal $X$-Bracing paling efektif dapat meningkatkan kekakuan, kekuatan dan stabilitas struktur.
\end{abstract}

Kata kunci: struktur baja, bracing, perpindahan, simpangan, kinerja

\section{PENDAHULUAN}

Salah satu metode untuk memodelkan kinerja struktur pada saat gempa adalah analisis static nonliner yaitu Static Pushover Analysis. Analisis ini lebih sederhana dan mampu menggambarkan perilaku inelastis dari setiap komponen struktur. Metode Pushover Analysis akan dihasilkan perilaku struktur secara keseluruhan mulai dari elastis, leleh hingga akhirnya runtuh. Pada metode ini dilakukan dorongan secara bertahap dengan menaikkan faktor pengali hingga akhirnya struktur bangunan leleh dan runtuh. Akan dihasilkan kurva Pushover yang menggambarkan hubungan antara gaya geser (V) dengan perpindahan titik acuan pada tiap lantai. Untuk menghindari terjadinya keruntuhan, maka bangunan dengan bentang panjang diperkecil dengan menggunakan pengaku diagonal. Pengaku diagonal merupakan salah satu komponen struktur yang berfungsi untuk menambah kekuatan dan kekakuan struktur, sehingga mampu mereduksi simpangan pada suatu bangunan. Pengaku diagonal juga mampu mengurangi waktu getar alami struktur. Dalam hal ini, massa bangunan dan kekakuan akan berpengaruh pada waktu getar alami. Hal ini disebabkan karena massa bangunan akan bertambah besar karena adanya pengaku diagonal sehingga jarak antar balok atau kolom menjadi lebih kecil dan kekakuan menjadi lebih besar. Dengan demikian, waktu getar alami struktur dengna menggunakan pengaku diagonal akan berkurang dibandingkan struktur tanpa menggunakan pengaku diagonal. 


\section{PENGAKU DIAGONAL}

Pengaku diagonal merupakan salah satu komponen struktur yang digunakan dalam bangunan tahan gempa . Penggunaan pengaku diagonal berfungsi menambah kekakuan bangunan, menahan beban lateral, menambah daktilitas dan kekuatan serta mampu meredam energi yang diakibatkan getaran-getaran. Secara umum, pengaku diagonal terbagi menjadi 2 macam yaitu, Eccentrically Braced Frame (EBF) dan Consentrically Braced Frame (CBF). Tipe pengaku EBF merupakan jenis pengaku diagonal dimana masing-masing pengaku diagonal akan terhubung dengan balok. Sedangkan tipe pengaku diagonal CBF merupakan jenis pengaku diagonal dimana sumbu utamanya bertemu atau saling memotong dalam satu titik struktur pengaku diagonal. Struktur Inverted $\mathrm{V}$, Single Diagonal dan X-Bracing pada studi analisis ini merupakan jenis dari tipe pengaku diagonal CBF.

\section{PEMODELAN STRUKTUR}

Bentuk struktur bangunan simetris dengan deskripsi sebagai berikut : Lokasi Bangunan : Kota Surabaya, Jenis Tanah: Tanah Lunak, Jenis Struktur: Baja Bertingkat, Mutu Baja: BJ-37, Fungsi Bangunan: Perkantoran, Jumlah Lantai: 5 dan 15 lantai, Elevasi Tiap Lantai: 4 m, Tinggi Total Bangunan: 20 dan 60 m, Luas per Lantai: $20 \mathrm{~m}$ x 20 m: $400 \mathrm{~m}^{2}$, Pembebanan: Beban Gempa statis linier dan non-linier, Beban Mati, Beban Hidup dan Beban Angin, Profil Kolom: WF 400 x 400 (Lantai 1-5), WF 350 x 350 (Lantai 6-10), WF 340 x 250 (Lantai 11-15), Profil Balok: WF 350 x 175, Profil Pengaku Diagonal: WF 100 x 100. Gambar denah struktur dapat dilihat pada Gambar 1. Pemodelan 3 dimensi model struktur dengan variasi pengaku diagonal dapat dilihat pada Gambar 2.

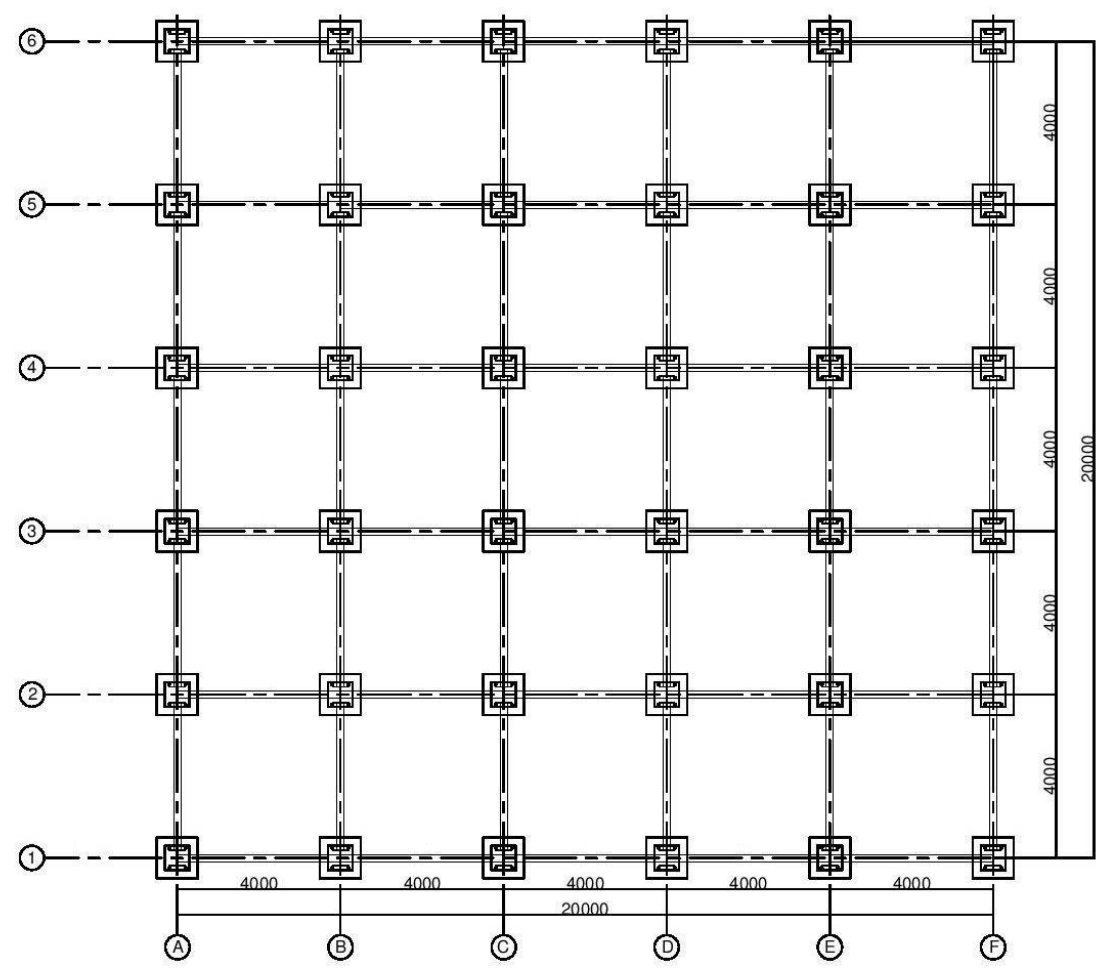


Gambar 1. Denah Struktur Gedung

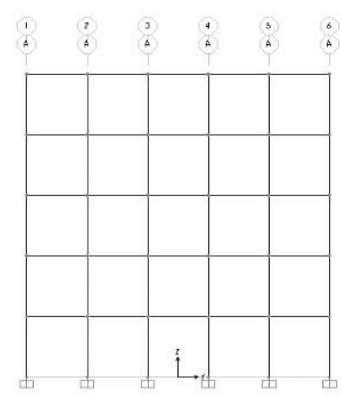

(a) Open Frame

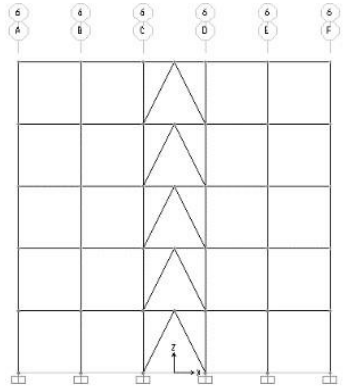

(c) Inverted $V$

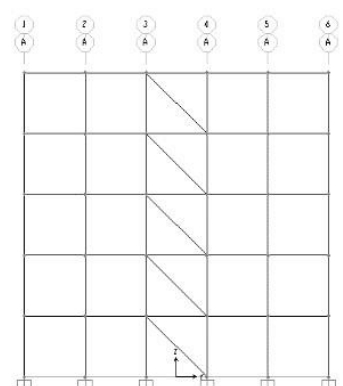

(b) Single Diagonal

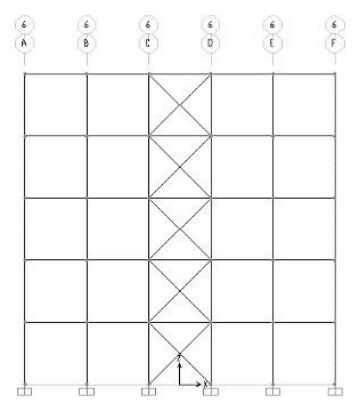

(d) X-Bracing

Gambar 2. Bentuk Struktur Pengaku Diagonal

Adapun tahap-tahap pada studi analisis ini adalah sebagai berikut, studi analisis dilakukan pemodelan struktur bangunan baja bertingkat 5 dan 15 lantai tanpa menggunakan pengaku diagonal, kemudian dilakukan analisis modal untuk menghitung waktu getar alami dan faktor efektivitas massa dan nilai geser dari pemodelan struktur bangunan, kemudian dilakukan pemodelan struktur bangunan dengan menggunakan pengaku diagonal baik Inverted V, Single Diagonal dan X-Bracing, setelah itu dilakukan analisis Pushover. Pada tahap ini dilakukan perbandingan perpindahan lateral, pengaruh penggunan pengaku diagonal terhadap daktilitas struktur dan kinerja struktur tanpa pengaku diagonal dengan menggunakan pengaku diagonal. Pada tahap akhir, diharapkan ada suatu kesimpulan dan saran berdasarkan hasil analisis yang diperoleh.

\section{HASIL DAN PEMBAHASAN}

Untuk mengetahui waktu getar alami, dilakukan analisis gempa dinamik pada struktur dengan menggunakan bantuan software SAP 2000 v14.

Waktu Getar Alami Maksimum Struktur Gedung (Ta) :

$$
\begin{aligned}
\mathrm{T}_{\mathrm{a}} & =\mathrm{Ct}_{\mathrm{t}} \mathrm{h}_{\mathrm{nx}} \\
& =0,0724 \times(20)^{0,8} \\
& =0,795 \mathrm{~s}
\end{aligned}
$$

Keterangan : 


$$
\begin{aligned}
\mathrm{T}_{\mathrm{a}} & =\text { Periode pendekatan fundamental }(\mathrm{s}) \\
\mathrm{C}_{\mathrm{t}} \text { dan } \mathrm{x} & =\text { Koefisien batas periode fundamental } \\
\mathrm{h} & =\text { Ketinggian struktur }(\mathrm{m})
\end{aligned}
$$

Waktu Getar Alami Maksimum Struktur Gedung ( $\mathrm{T}_{\mathrm{a}}$ ) pada software SAP 2000 v14 adalah $\mathrm{T}_{\mathrm{a}} / \mathrm{T}_{\text {eff }}=0,476 \mathrm{~s}$.

$$
\begin{aligned}
\mathrm{T}_{\mathrm{a}} \text { Perhitungan } & \geq \mathrm{T}_{\mathrm{a}} \mathrm{SAP} 2000 \\
0,795 \mathrm{~s} & \geq 0,476 \mathrm{~s}
\end{aligned}
$$

Dari hasil analisis perhitungan dan software SAP 2000, diperoleh kesimpulan bahwa nilai waktu getar alami tanpa menggunakan pengaku diagonal masih memenuhi persyaratan yang berlaku dalam SNI 1726 - 2012.

Waktu Getar Alami Maksimum Struktur Gedung ( $\mathrm{T}_{\mathrm{a}}$ ) pada software SAP 2000 v14 untuk gedung dengan tambahan pengaku diagonal adalah :

$$
\begin{array}{ll}
\text { Single Diagonal } & =0,427 \mathrm{~s} \\
\text { Inverted } V & =0,417 \mathrm{~s} \leq 0,795 \mathrm{~s} \\
X \text {-Bracing } & =0,393 \mathrm{~s}
\end{array}
$$

Dari hasil analisis perhitungan dan software SAP 2000, diperoleh kesimpulan bahwa nilai waktu getar alami gedung dengan tambahan struktur pengaku diagonal juga memenuhi persyaratan yang berlaku dalam SNI 1726 - 2012 dengan nilai yang lebih kecil dibandingkan dengan nilai waktu getar alami gedung Open Frame.

Perpindahan pada Struktur Gedung

Perpindahan struktur ditinjau pada joint tengah sebagai diafragma pada struktur gedung. Perpindahan antar lantai pada pemodelan struktur tanpa pengaku diagonal dapat dilihat pada Gambar 3. 


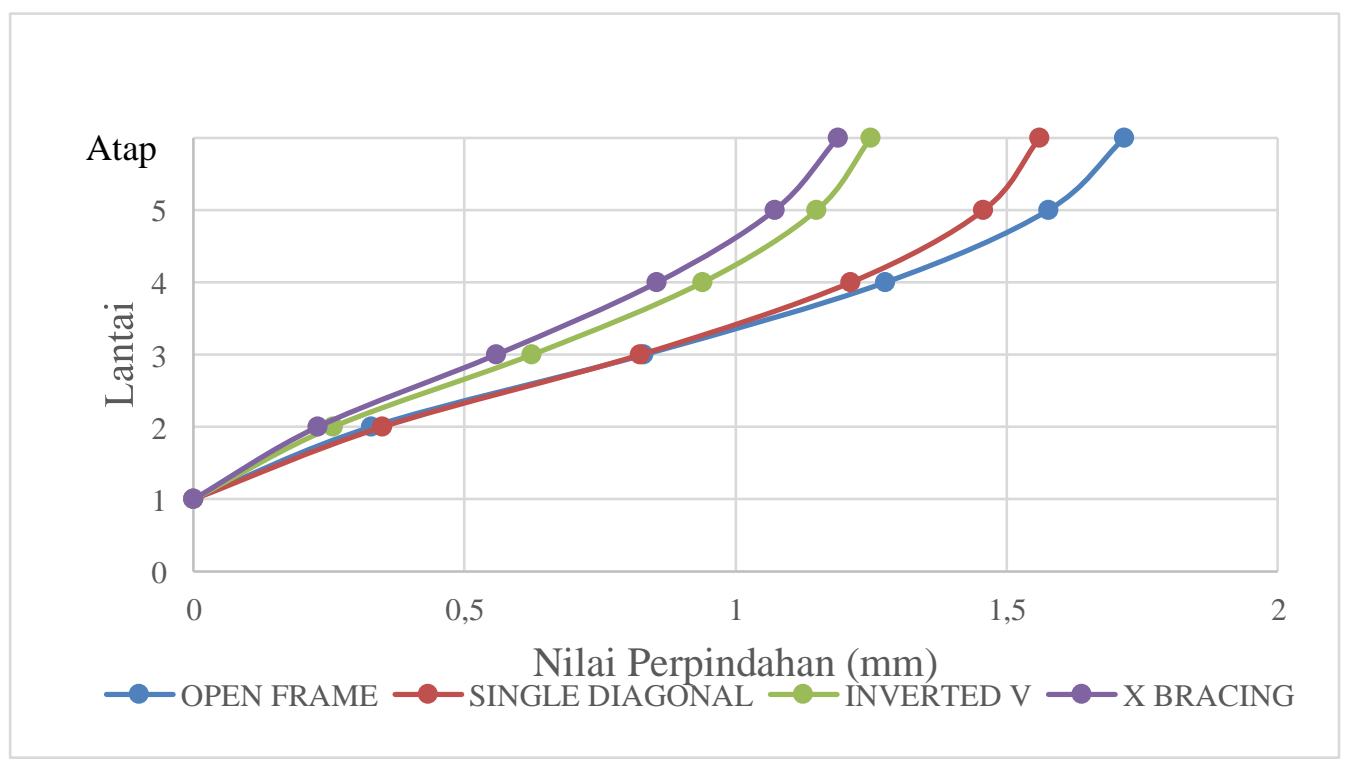

Gambar 3 : Perpindahan Antar Lantai Gedung 5 Lantai Pada Arah X

Dari hasil kontrol perpindahan antar lantai gedung 5 lantai pada arah $\mathrm{x}$, dapat diketahui nilai presentase reduksi gedung jenis Open Frame terhadap Single Diagonal mampu mereduksi perpindahan hingga mencapai 9,11\%, Open Frame terhadap Inverted $V$ 27,24\% dan Open Frame terhadap X-Bracing 30,78\%. Sehingga dapat dikatakan bahwa pengaruh perkuatan pengaku diagonal sangat besar terhadap perpindahan struktur yang terjadi akibat beban gempa.

Berikut adalah grafik ratio simpangan yang dimiliki masing - masing jenis gedung 5 lantai :

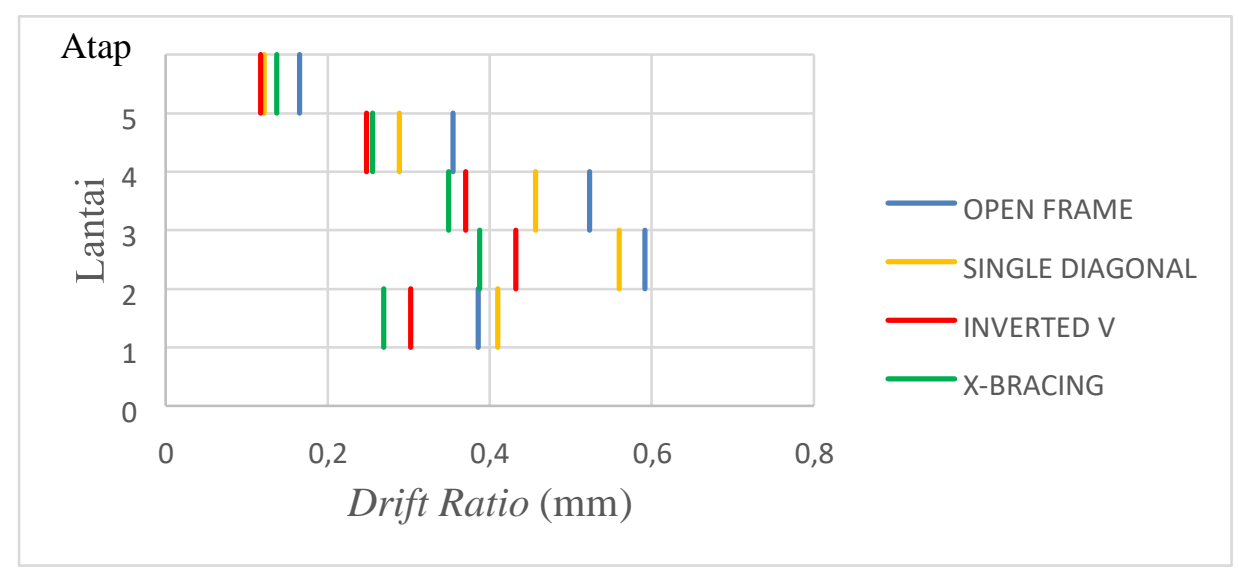

Gambar 4 : Grafik Drift $(\Delta)$ Ratio Gedung 5 Lantai

Berdasarkan Gambar 3 dan 4 dari lantai 1 - 5, dapat dilihat bahwa gedung 5 lantai, jenis gedung Open Frame memiliki nilai perpindahan dan simpangan yang paling besar. Sedangkan jenis gedung dengan tambahan pengaku diagonal $X$-Bracing memiliki nilai perpindahan dan simpangan yang paling kecil, disusul dengan gedung dengan tambahan 
pengaku diagonal Inverted $V$ dan Single Diagonal. Sehingga 3 jenis gedung dengan tambahan pengaku diagonal mampu mereduksi perpindahan serta simpangan.

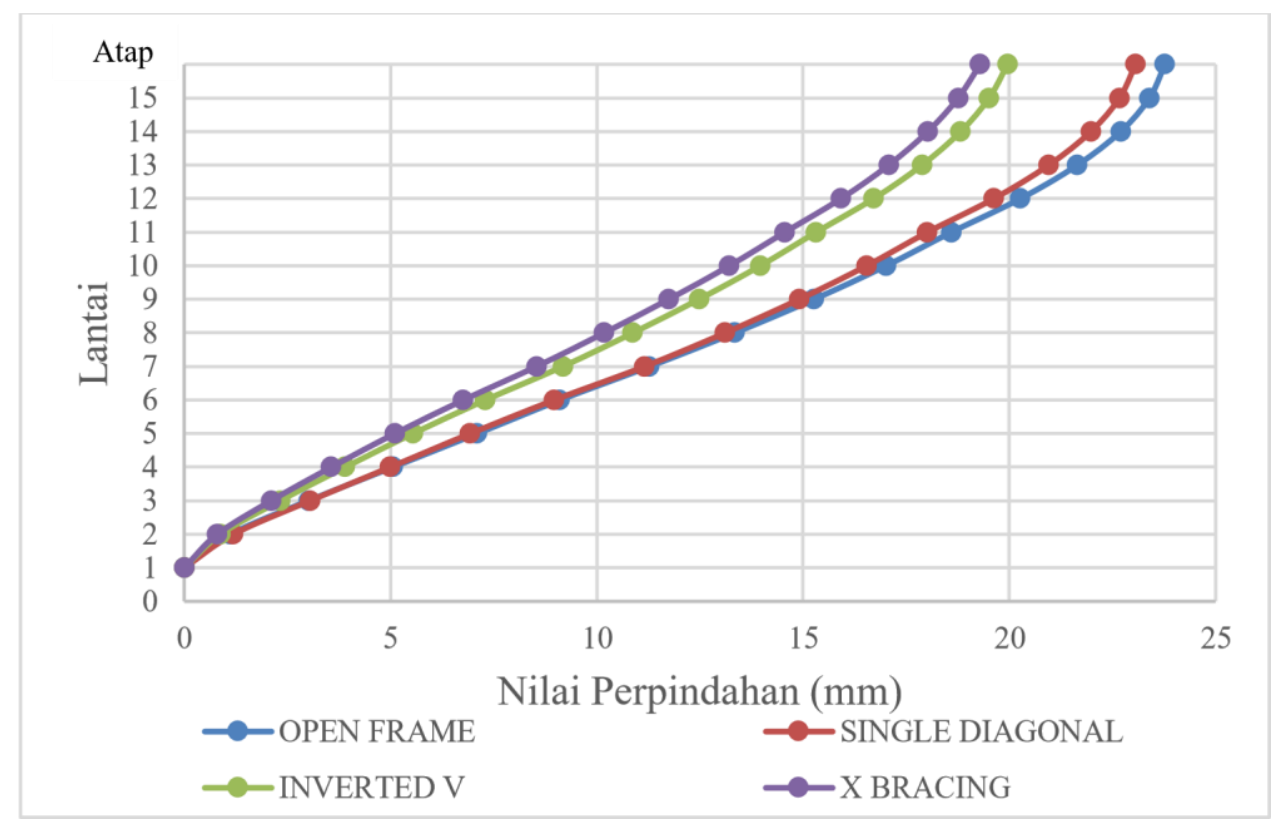

Gambar 5 : Perpindahan Antar Lantai Gedung 15 Lantai Pada Arah X

Dari hasil kontrol perpindahan antar lantai gedung 15 lantai pada arah x, dapat diketahui nilai presentase reduksi gedung jenis Open Frame terhadap Single Diagonal mampu mereduksi perpindahan hingga mencapai 3,00\%, Open Frame terhadap Inverted $V$ 16,04\% dan Open Frame terhadap X-Bracing 18,84\%. Sehingga dapat dikatakan bahwa pengaruh perkuatan pengaku diagonal sangat besar terhadap perpindahan struktur yang terjadi akibat beban gempa.

Berikut adalah grafik ratio simpangan yang dimiliki masing - masing jenis gedung 15 lantai :

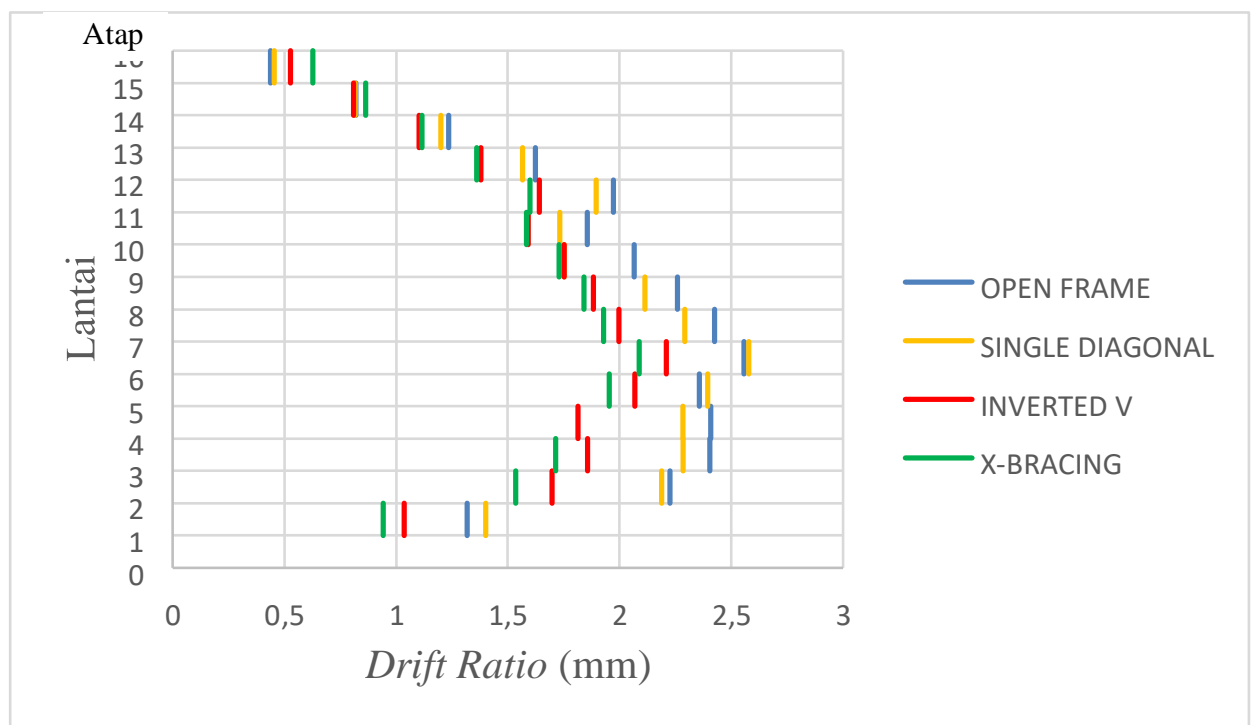


Berdasarkan Gambar 5 dan 6 dari lantai 1 - 15, dapat dilihat bahwa gedung 15 lantai, jenis gedung Open Frame juga memiliki nilai perpindahan dan simpangan yang paling besar. Sedangkan jenis gedung dengan tambahan pengaku diagonal X-Bracing memiliki nilai perpindahan dan simpangan yang paling kecil, disusul dengan gedung dengan tambahan pengaku diagonal Inverted $V$ dan Single Diagonal.

Dari hasil analisis Pushover diperoleh hasil roof drift $(\Delta) /$ performance point gedung Open Frame 5 lantai arah X sebesar 65,19 mm dan arah Y sebesar 99,44 mm. Sedangkan untuk gedung Single Diagonal 5 lantai arah X sebesar 57,55 mm dan arah Y sebesar 86,17 mm.

Arah X

$$
\begin{aligned}
\text { Drift Ratio } & =\Delta / \mathrm{H} \\
& =65,19 / 20000 \\
& =0,0033
\end{aligned}
$$

Arah Y

$$
\begin{aligned}
\text { Drift Ratio } & =\Delta / \mathrm{H} \\
& =99,44 / 20000 \\
& =0,0050
\end{aligned}
$$

Tabel 1 : Drift Aktual dan Tingkat Kinerja Pada Gedung 5 Lantai

\begin{tabular}{|c|c|c|c|c|}
\hline Jenis Gedung & $\begin{array}{c}\text { Arah X } \\
(\mathbf{m m})\end{array}$ & $\begin{array}{c}\text { Tingkat Kinerja } \\
\text { Struktur }\end{array}$ & $\begin{array}{c}\text { Arah Y } \\
(\mathbf{m m})\end{array}$ & $\begin{array}{c}\text { Tingkat Kinerja } \\
\text { Struktur }\end{array}$ \\
\hline Open Frame & 0,003 & $\begin{array}{c}\text { Immediate } \\
\text { Occupancy }\end{array}$ & 0,005 & $\begin{array}{c}\text { Immediate } \\
\text { Occupancy }\end{array}$ \\
\hline Single Diagonal & 0,003 & $\begin{array}{c}\text { Immediate } \\
\text { Occupancy }\end{array}$ & 0,004 & $\begin{array}{l}\text { Immediate } \\
\text { Occupancy }\end{array}$ \\
\hline Inverted $\boldsymbol{V}$ & 0,003 & $\begin{array}{l}\text { Immediate } \\
\text { Occupancy }\end{array}$ & 0,004 & $\begin{array}{l}\text { Immediate } \\
\text { Occupancy }\end{array}$ \\
\hline $\boldsymbol{X}$-Bracing & 0,002 & $\begin{array}{l}\text { Immediate } \\
\text { Occupancy }\end{array}$ & 0,003 & $\begin{array}{l}\text { Immediate } \\
\text { Occupancy }\end{array}$ \\
\hline
\end{tabular}

Tabel 2 : Drift Aktual dan Tingkat Kinerja Pada Gedung 15 Lantai

\begin{tabular}{|c|c|c|c|c|}
\hline Jenis Gedung & $\begin{array}{c}\text { Arah X } \\
(\mathbf{m m})\end{array}$ & $\begin{array}{c}\text { Tingkat Kinerja } \\
\text { Struktur }\end{array}$ & $\begin{array}{c}\text { Arah Y } \\
(\mathbf{m m})\end{array}$ & $\begin{array}{c}\text { Tingkat Kinerja } \\
\text { Struktur }\end{array}$ \\
\hline Open Frame & 0,018 & Damage Control & 0,024 & $\begin{array}{c}\text { Structural } \\
\text { Stability }\end{array}$ \\
\hline
\end{tabular}


VOLUME 4 NOMOR 1 JUNI 2020

\begin{tabular}{|c|c|c|c|c|}
\hline Single Diagonal & - & - & - & - \\
\hline Inverted V & - & - & - & - \\
\hline X-Bracing & 0,016 & Damage Control & - & - \\
\hline
\end{tabular}

Dari hasil analisis dengan menggunakan target displacement sebesar 2 meter, dapat diketahui bahwa tingkat kinerja struktur baik 5 dan 15 lantai untuk masing-masing jenis gedung masih dalam range IO (Immediate Occupancy) dan DC (Damage Control), serta terdapat beberapa jenis gedung dengan tambahan pengaku diagonal yang tidak memotong demand spectrum untuk kota Surabaya dengan kondisi tanah lunak sehingga tidak dapat diketahui kinerja struktur secara keseluruhan. Penambahan pengaku diagonal pada masing-masing gedung tersebut sangat membantu mengurangi besarnya respon struktur terhadap gaya gempa.

\section{KESIMPULAN}

Berdasarkan hasil studi analisis terhadap gedung tanpa pengaku diagonal dan gedung dengan tambahan pengaku diagonal (Single Diagonal, Inverted $V$ dan X-Bracing) dapat diambil kesimpulan sebagai berikut :

1. Tambahan pengaku diagonal dapat mengurangi periode struktur gedung serta mereduksi displacement struktur. Reduksi nilai displacement pada gedung 5 lantai arah x struktur Open Frame dengan gedung penambahan pengaku diagonal Single Diagonal, Inverted $V$ dan X-Bracing berturut-turut sebesar $9,11 \%, 27,24 \%$, dan $30,78 \%$. Dan pada gedung 15 lantai arah x struktur Open Frame dengan gedung penambahan pengaku diagonal Single Diagonal, Inverted $V$ dan $X$-Bracing berturutturut sebesar 3,00\%, 16,04\%, dan 18,84\%.

Sehingga dapat disimpulkan bahwa, penambahan struktur pengaku diagonal dengan tipe $X$-Bracing paling efektif daripada kedua jenis pengaku diagonal lainnya dengan nilai simpangan paling kecil, serta presentase reduksi perpindahan yang paling besar.

2. Dari hasil Pushover Analysis yang dilakukan, dapat dibuktikan bahwa gedung dengan penambahan pengaku diagonal mengalami peningkatan perkuatan dibandingkan dengan gedung tanpa pengaku diagonal.

3. Tingkat kinerja struktur dengan perkuatan pengaku diagonal mayoritas tergolong dalam kategori IO (Immediate Occupancy) dan DC (Damage Control), serta terdapat beberapa jenis gedung dengan tambahan pengaku diagonal yang tidak memotong demand spectrum untuk kota Surabaya dengan kondisi tanah lunak sehingga tidak dapat diketahui kinerja struktur secara keseluruhan. Perkutan pengaku diagonal pada kondisi gedung tersebut sangat membantu mengurangi besarnya respon struktur terhadap gaya gempa. Sehingga, semakin banyak pemberian pengaku diagonal maka pengaruh respon struktur juga semakin besar.

\section{DAFTAR PUSTAKA}

1. American Institute of Steel Construction. (2010) ASCE/SEI 7-10 : ANSI/AISC 36010, Speccification for Structural Steel Buildings, 2010, Chicago. 


\section{NAROTAMA JURNAL TEKNIK SIPIL \\ e-ISSN: $2460-3430$ \\ VOLUME 4 NOMOR 1 JUNI 2020}

2. European Convention for Constructional Steelwork (ECCS). (2017). Desgin of Steel Structures for Buildings in Seismic Areas: Eurocode 8. Sersilito, Portugal.

3. Halim, Clement Kristianto. (2020). Studi Analisis Variasi Tipe Pengaku Diagonal Pada Struktur Bangunan Baja Bertingkat. Surabaya : Universitas Widya Kartika.

4. Hamzah. (2010) Seminar Nasional VI 2010 Teknik Sipil ITS. Studi Perbandingan Struktur Jack Up Platformsistem Concentrically Braced Frames (CBF) dan Sistem Ecccentrically Braced Frames (EBF) Tubular Link. Surabaya.

5. Pusat Studi Gempa Nasional \& Pusat Litbang Perumahan dan Permukiman. (2017). Peta Sumber dan Bahaya Gempa Indonesia Tahun 2017.

6. Pedoman Perencanaan Pembebanan Indonesia untuk Rumah dan Gedung (PPIUG). (1987).

7. Ronald D. Ziemian. (2010). Guide to Stability Design Criteria for Metal Structures. New Jersey.

8. Schodek. (2014). Structures ( $7^{\text {th }}$ Edition). New Jersey.

9. Standar Nasional Indonesia. (2012). SNI 03-1726-2012. Tata Cara Perencanaan Ketahanan Gempa untuk Struktur Bangunan Gedung dan Non-Gedung. Jakarta: Badan Standarisasi Nasional.

10. Standar Nasional Indonesia. (2013). SNI 03-1727-2013. Beban Minimum untuk Perancangan Bangunan Gedung dan Struktur Lain. Jakarta: Badan Standarisasi Nasional.

11. Standar Nasional Indonesia. (2015). SNI 03-1729-2015. Tata Cara Perencanaan Struktur Baja untuk Bangunan Gedung. Jakarta: Badan Standarisasi Nasional. 